The groups recently contacted and studied by the State Museum expedition probably represent the only stoneusing indigenous peoples in the whole of southern Africa. Two groups calling themselves OvaTjimba were contacted; the first of these, the Okombambi group, consisted of fourteen individuals who normally lived in the heights of the Baynes Mountains. Details of their appearance, dress and decoration, and habitations were recorded by the expedition, and specific information about the equipment used for hunting and gathering was obtained. Nothing could be ascertained of their religion, and they appeared to have neither art nor music. The second group, called Otjinungua, consisted of only four individuals, but in general terms these seemed to conform to the Okombambi group in physical appearance and in material culture. Both extensively utilize the products of their limited high-altitude environment, using wood, skins, bone and stone, supplemented in both eases by scavenging in abandoned OvaHimba villages for cloth and iron. The stone-working methods observed consisted of direct percussion and block-on-block; the differences in detail between the two groups may havo been due as much to the limited quantity of the ovidence as to different traditions.

The authors of this report have also succeded in establishing the true indigenous nature of these groups, by producing evidence which seems to show that these people do not represent OvaTjimba who have lost their cattle, but must be considered as a group whose economy has never been based on domestication. Further expeditions are planned, and it is to be hoped that this unique opportunity to investigate an isolated group living under conditions which must be relevant to those of prehistoric times will be fully exploited.

JoHN M. COLES

\title{
DRIFT REHABILITATED
}

$A^{\text {F }}$ TER many years of suspicion and acrimonious discussion the seal of respectability has firmly been set on the theory of continental drift by the publication of A Symposium on Continental Drift* as a volume of the Philosophical Transactions of the Royal Society. For the first time Continental Drift is discussed with as little reference to Wogener as was formerly accorded to Taylor. It avoids the Seylla of inconclusive diseussion of geological and palaeontological data on the Wegener-Du Toit models, and the Charybdis of inadequate mechanism. The first pitfall is avoidod by discounting data so obviously insufficiently precise and relying on data from palaeomagnetism to establish a prima facie case for drift, and the second by concentrating on the most plausible mechanism so far proposed, mantle convection currents, and assembling the variety of data from modern petrologypetrochemistry, oceanographic geophysics, physies and geochemistry which have a bearing upon it.

The contributions to the Symposium are divided under four heads, each with discussion. These are "Continental Reconstructions". "Horizontal Displacements in the Earth's Crust", "Convection Currents and Continental Drift", and "Physies of Convection Currents in the Earth's Mantle".

The first section, largely introductory, opens with articles by P. M. S. Blackett, T. S. Westoll and S. K. Runcorn, which, if they presont little that is new, nevertheless set the stage for the Symposium. This soction is completed by Creer's survey of data from the southern hemisphere, much of it his own, and the article by $\mathbf{E}$. Bullard, J. E. Everett and A. G. Smith on the fit of the continents around the Atlantic. In view of Westoll's exposure of the inadequacy of many of the geological data used in earlier discussions and the claim in each of the first three articles that there is good agreement between palaeoclimates and palaeomagnetism, it would perhaps have been of value if the quantitative work on palaeoclimates by Irving or Blackett had been recorded. For, in the fourth article, Creer's discussion of Devonian reconstructions overlooked the siting in polar rogions of a North African Devonian fauna similar to one considered in Europe as a warm water fauna on palaeontological grounds and tropical on palaeomagnetic grounds, and results in the austral fauna generally considered as a cold water fauna in South Africa coming to rest in latitude $30^{\circ}$.

The article by Bullard, Everett and Smith removes once and for all from the realms of speculation the fit of the continents bordering the Atlantic. This fit for the

* Phil. Trans. Roy. Soc., A, 258, No. 1088, 1965: Organized for the Royal Society by Prof. P. M. S. Blackett, F.R.S., Sir Edward Bullard, F.R.S., and Prof. S. K. Runcorn, F. R.S. Pp. X+1-323+A1-A6. (London: The Royal
Socinty, 1965.) 1408.; 21 dollars.
North Atlantic is used by contributors to the third session (J. A. Miller and F. J. Fitch), whose assembly of radiometric and tectonic information would have gladdened the heart of F. B. Taylor. However, the attempt to reassemble the whole Atlantic, as J. L. Worzel points out, runs into difficulties as far as Central America and Mexico are concerned. The geological history of the Atlantic forms part of an article by J. T. Wilson.

The second section, on "Horizontal Displacements in the Earth's Crust", covers recent oceanographic work on transcurrent faults, ridge-rise systems, and rifting. The section title unfortunately precludes a review of the heat. flow data. This section is completed by an article on continental transcurrent faulting. Mostly factual, the data are objectivoly described and tentative interpretation is attempted.

The final section, on "The Physics of Convection Currents in the Earth's Mantle", provides the geologist with present-day viows of geophysicists on the state of the mantle, and although G. J. F. MacDonald shows that another interpretation in terms of mantle strength is possible, overwhelmingly, discussion is of convection. The conditions for thermal convection for a mantle of nonNewtonian viscosity are described by E. Orowan, while $J$. Verhoogen considers the effect of phase change on convection. Convection involving the whole mantle is proposed by Runcorn, and Tozer discusses convection confined to the upper part of the mantle. The former puts forward a general theory to account for "the most puzzling feature of continental drift; that it should have occurred in the last 5 per cont of the Earth's life", for it is hard to see why, if drift has been active during the past $250 \mathrm{~m} . \mathrm{y}$., it should not have occurred in earlier times. J. T. Wilson suggests, on the other hand, that "periodic break-up of continents . . may have happened several times", a view with which the reviewer concurs. The reconstrueted North Atlantic as shown by Bullard must have boen broken through during much of the Palaeozoic by a geosyncline bordered by shelf seas. The steady sinking and later folding and uplift have to bo explained in some way. If Wilson is right, the convection pattern suggested by D. C. Tozer may provide a better explanation than Runcorn's. Questions of this nature will continue to stimulate research and indicate how ideas are moving away from the initial simple pattern to the recognition of a more complex, and as yet uncertain, design.

In stimulating such interest, the Symposium succeeds. and thanks are due to the organizers and editor for the assembly of so much interesting material. If the price, at more than $£ 2$ per hundred pages, seems high. was respectability ever cheaply bought? 